\title{
Perinatal Acoustic Communication in Birds: Why Do Birds Vocalize in the Egg?
}

\author{
Marion Rumpf ${ }^{*}$ and Barbara Tzschentke
}

Humboldt-University of Berlin, Institute of Biology, 10115 Berlin, Germany

\begin{abstract}
In this review the development of acoustic communication between embryos or between embryos and chicks as well as between embryos/chicks and the breeding parents will be addressed. Special emphasis is given to the impact of embryonic acoustic signals for hatching synchronization.

In the Muscovy duck (Cairina moschata L.f. domestica) clicking sound communication is absolutely essential for a synchronized hatching. The mechanism underlying this special case of communication is a synchronization of clicking rates. In a clutch, embryos adapt their clicking rates to each other. Clicking rates of less developed embryos rose faster (acceleration) than clicking rates of more developed embryos (retardation). No evidence was found that vocalization of embryos, chicks and parents improve hatching synchronization.

Although, many authors assume that prenatal acoustic interaction by vocalization (an exchange of acoustic signals) exists, in the Muscovy duck it was shown that an acoustic interaction started when the first embryo had hatched. Specific call types serve as communication-releasing signals. Acoustic mother-duckling interaction developed later and gradually during the process of nest-leaving also based on specific call types.
\end{abstract}

Measurements on sound transmission indicate that all embryos within a clutch are in mutual acoustic contact.

Keywords: Perinatal acoustic communication, Hatching synchronization, Muscovy duck, Clicking sounds, Vocalization.

\section{INTRODUCTION}

Why do birds vocalize in the egg? Do the birds really use the ability to vocalize for acoustic communication in the prenatal period? For acoustic communication the following preconditions are necessary: hearing sensitivity, sound production and sound transmission from egg to egg. We know that birds are able to produce and perceive sounds before hatching, especially in precocial bird species. However besides our own investigations, no studies on sound transmission exist at present. Although many authors presume a prenatal acoustic communication [1-3] there is a lack of detailed studies [4,5]. Using the Muscovy duck (Cairina moschata L. f. domestica) as a model species the development of the acoustic communication between chicks/embryos and the development of the embryo-maternal communication $[6,7]$ under field, laboratory and industrial conditions were investigated. This precocial species is well suited for studies of the prenatal period because of its long incubation time (about 35 days) and of its long period of prenatal vocalization (about 2-3 days) [8].

\section{HEARING SENSITIVITY AND PERCEPTION OF EXOGENOUS ACOUSTIC STIMULI}

In precocial species hearing sensitivity starts in the second half of incubation [9-11], in semialtricial birds in the

*Address correspondence to this author at the Humboldt-University of Berlin, Institute of Biology, WG Perinatal Adaptation, Philippstraße 13, Haus 2, 10115 Berlin, Germany; Tel: 049-30-2093 6213; Fax: 049-30-2093 6008; E-mail: marion.rumpf@staff.hu-berlin.de last third of incubation and in altricial birds around hatching [11].

In mallard embryos and ducklings (Anas platyrhynchos L. $f$. domestica), for instance, sensitivity to mid frequency range $(1,1.5,2,3 \mathrm{kHz})$ appeared $1-2$ days later within the prenatal period compared to low frequencies, but improved rapidly during the prenatal period corresponding to the embryos' and ducklings' own vocalization. Sensitivity to mid frequency range was almost complete by hatching [12]. Auditory sensitivity in the low and high frequency ranges continued to develop after hatching. First responses of the brainstem auditory evoked potential to tone pips (500-1500 $\mathrm{Hz}$ ) were achieved on E (embryonic day) 21 in mallard ducks. First behavioural responses to sound were achieved one day later, on E 22 [12]. In laboratory experiments, on this day the mallard maternal call caused a reliable rate of bill clapping, two days before embryos begin to vocalize [13, 14].

In domestic chickens (Gallus gallus L. f. domestica) cochlear ganglion neurons exhibited a profound insensitivity to sound from E 12 to E 16 [15]. In this prehearing period the cochlea functions as a signal generator (spontaneous activities), not as a sensor. In the following period (E 16-E 19) the cochlea begins to detect and encode sound, which is regarded as the beginning of hearing [15]. Measured by footplate stimulation frequency selectivity matures rapidly during $\mathrm{E}$ 16-E $18(170-4,478 \mathrm{~Hz})$ and the range is comparable with the frequency range of the hatchlings [15]. The auditory threshold levels between late embryos and hatchlings differed significantly, when using airborne stimulation, and were nearly the same when stimulated with 
the footplate stimulation [15]. The responsiveness to high frequencies improved in chickens around hatching and in the 2 weeks post hatching [15].

In summary, precocial bird embryos are able to respond to exogenous acoustic stimuli during the last $20 \%$ of incubation. In the Muscovy duck, first heart rate responses upon sound application were measured on E 27 [16]. Further, bird embryos may respond to acoustic stimuli by raising the bill clapping rate $[1,17-21]$, by a greater rate of foot movements [21,22], opening the eyes [24] or vocalizing more $[17,23-25]$. Additional to the prenatal hearing sensitivity the vibration sense is well developed in the last quarter of incubation. In this period the range of best hearing $(300-600 \mathrm{~Hz})$ is a range that could be important for clicking sound communication [26, see next paragraphs].

\section{SOUND PRODUCTION}

\section{First Calls}

The avian embryo produces the first calls before it tips the bill into the air chamber, before the so-called internal pipping. Gas exchange via Chorioallantois and the lungs allows initial respiration movements [27]. These calls are low single calls and occur irregularly [11,28]. They consist of an inverse u-shaped form considered to be the most basic form of call. This shape is characteristic for first vocalizations, which are not controlled by the syrinx muscles (Fig. 1) [11]. Precocial species like the Peking duck emit these calls about $30 \mathrm{~h}$ before hatching [11] or $48 \mathrm{~h}$ before internal pipping in the Muscovy duck, respectively [28] An altricial species like the Red Throated Pipit (Anthus cervina Pall.) emits these calls $2 \mathrm{~h}$ before pipping the eggshell (external pipping) [11]

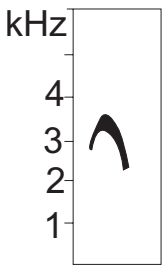

Fig. (1). Single call [sonogram] of a Muscovy duck embryo before internal pipping [28].

\section{Clicking Sounds}

Accompanying with the development of breathing the embryos begin to regularly produce so-called clicking sounds [29], clicks or clicking noises, which are audible to the human ear. It can be excluded that they are produced by the egg tooth tapping against the eggshell, as some authors previously supposed $[30,31]$ or by bill-clapping [32, 33]. Clicks are produced synchronously with respiration movements $[34,35]$. They might be caused by the fluid in the respiratory tract [36], within the glottis [34], produced from the cartilaginous parts in the superior larynx $[11,37]$ or might emerge when the membrana tympaniformae interna is forced against the opposite bronchial wall due to the Bernouilli-effect [38]. Prenatal clicks are accompanying noises of respiration and not a real vocalization, controlled by the syrinx. This is important when we look at the function of clicking and vocalization. In the present paper, the authors differentiate clicking from vocalization. In the Muscovy duck first clicking sounds were observed once the inner eggshell was penetrated [8].

In all bird species clicks are very short $(10-30 \mathrm{~ms})$ and have a wide range of frequencies up to about $4 \mathrm{kHz}$ with the highest intensity at low frequencies [2, 3, 28]. Clicks are produced during inspiration and expiration or during inspiration or expiration (Fig. 2).

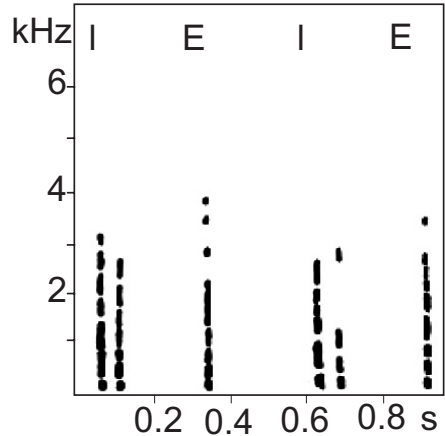

Fig. (2). Clicking calls (sonogram) of a Muscovy duck embryo 2 days before hatching [modified from 8, 28]. I-inspiration; Eexpiration.

Inspiration and expiration were summed together and referred to as one click. The clicking rate (number of clicks per minute) corresponded with the audible respiration frequency. The development of the clicking rate of one Muscovy duck embryo from the first clicks to the hatching is shown in Fig. (3).

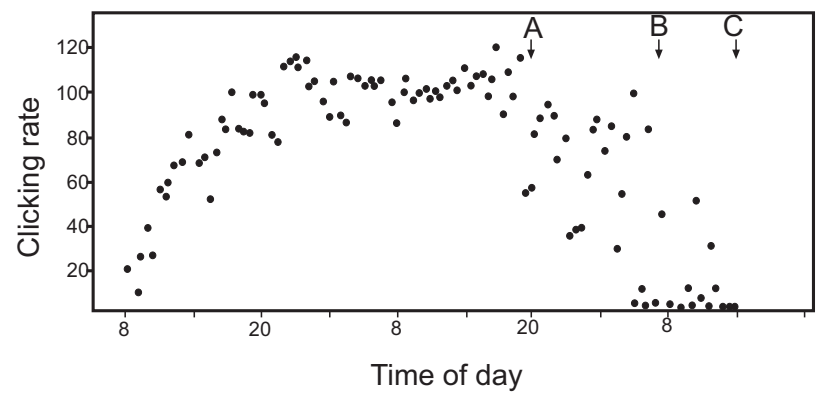

Fig. (3). Prenatal clicking rate of a single embryo (measured every 30 minutes), method described in [8]. A- External pipping. BCutting (pipping while rotating). C- Hatch.

Clicking rate increased until it achieved a plateau level different from one individual to the other (in the Muscovy duck on average 120; max. 140, min 80). At the level of the highest clicking rate duck embryos penetrated the outer eggshell (in an abnormal position the inner and outer shell together). Then the hatching process started when the embryo turned around while pushing the egg tooth against the shell to open it. In this stadium the clicking sounds become irregular, because the respiration is too flat, therefore clicks were not audible by the microphones. Only sometimes these flat respiration movements were disrupted by deep audible breathing movements [39]. After hatching, clicking rate increased again (about 50-95 clicks/min) but without reaching the highest prenatal level. $4 \mathrm{~h}$ after hatching no clicking was measured in the Muscovy duck. Similar to respiration rate [40] clicking rate depended on temperature [28]. When duck embryos click regularly (2 days before 
hatching) higher temperatures resulted in higher clicking rates. Above $37.7^{\circ} \mathrm{C}$, flat breathing without clicking was registered.

Clicking sounds are common among bird embryos [2, 3, $5,11,41]$. Clicking is known, for instance, from quails [35, 36, 43-51] ducks [41], geese [41], curlews [51] and chicken [41], but investigations on the development of prenatal clicking rate are only available for Muscovy ducks [8, 28] and quails [35].

The clicking sounds do not essentially vary between the bird species [2, own unpublished results]. It can be hypothesized that an interspecies clicking communication might be possible and beneficial for species like ducks where clutches from different species or different parents have been observed.

\section{Vocalizations}

Beginning with penetrating the inner egg membrane a species-specific sound repertoire develops gradually. As it is difficult to decide about the function of the variety of vocalizations in the egg most authors described the vocalization in the bird embryo based on the form of the sonograms [5, 6, 52]. Based on the sonograms we can distinguish vocalizations of either ascending or descending frequencies or vocalizations of descending and ascending frequencies. And we can consider syntactic parameters such as the repetition rate or the duration of the calls. Vocalizations of ascending frequency modulation are often interpreted as comfort signals (=pleasure calls) [52], whereas distress calls consisting of at least two or more calls of descending-bell shaped frequency modulation are interpreted as discomfort signals.

However, we should be aware that this grouping is already an interpretation, which might be different from the actual information content. From the investigation in the Muscovy duck we know that some vocalizations play a special role for acoustic communication. Here it was the double call consisting of 2 elements of descending frequency modulation and with the second element of a higher maximal frequency and the trill call consisting of at least 2 elements of ascending and descending frequency modulation (example in Fig. (9)). The last mentioned calls are also referred to as contentment calls [5]. Alarm calls are not produced by bird embryos [2, 53-55].

During the prenatal period vocalization activity rises that as is especially evident in those bird species having a long period of prenatal vocal production. Fig. (4) shows the vocalization activity of the Muscovy duck [6]. The number of vocalization increased within the 3 days before hatching as studied in single and in paired embryos (Fig. 4). Similar results of increasing vocalization activity are published for naturally incubated domestic chicken embryos [52].

In the Muscovy duck, the percentage of certain vocalization types did not change within the prenatal period until the hatching process begins. Descending calls were the most frequent call types $(46 \%)$. The range of fundamental frequency $(1.8-5 \mathrm{kHz})$ remained the same within the prenatal period in the Muscovy duck. The duration of distress call elements increased during the prenatal period [6]. When comparing vocal activity of further developed chicken embryos (external pipped) with less developed embryos (internal pipped) higher call frequency, call duration and a higher number of elements per call were detected in external pipped embryos corresponding to the maturation of the lungs and an increased airstream through the lungs [56].

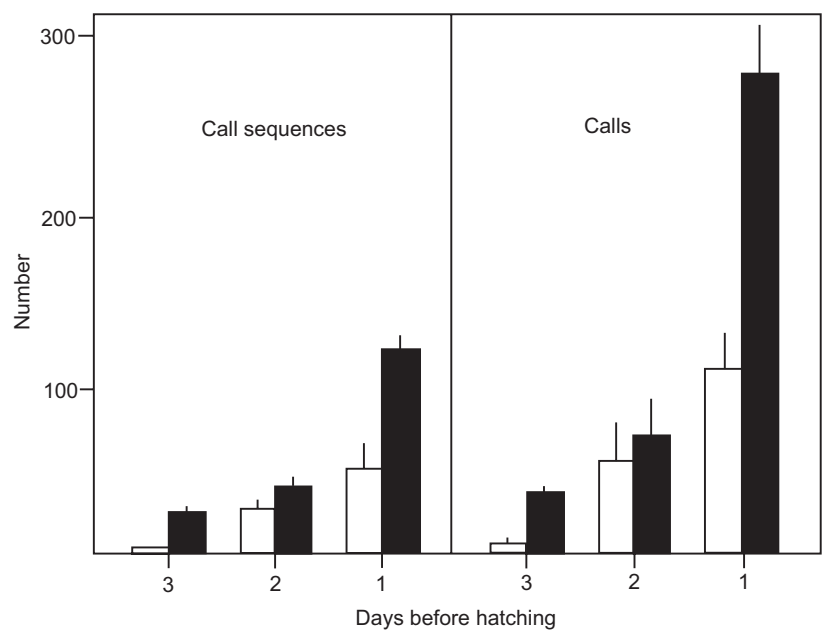

Fig. (4). Prenatal vocal activity of single (white columns) and paired embryos (black columns). Mean value of three embryos $(p<0.01$ three days and one day before hatching, NS 2 days before hatching) [6].

\section{SOUND TRANSMISSION}

Whether an embryo can hear only its neighbour, or all the embryos in the clutch depends on sound transmission between the eggs. Interestingly, up to now, no studies have been published concerning this aspect. Thus, the authors present their results on sound transmission (Fig. 5) [28], which were measured in muted embryos at E 32 before the outer eggshell was pipped (2-3 days before regular hatching) using an artificial sound emitter (broad band noise signal in the range of $50-5000 \mathrm{~Hz}$, in the range of the embryos own sound production frequencies). The artificial sound was presented to the first egg and was measured on each of the 9 following eggs in 10 lengthwise Fig. 5A) or crosswise positioned eggs (Fig. 5B).

Summarizing all measured frequencies, sound absorption in crosswise positioned eggs was by 5-10 dB greater compared with that of lengthwise positioned eggs [28]. Above $3 \mathrm{kHz}$ no frequency dependence of sound absorption was measured (Fig. 5). As sound absorption from the first to the 6th egg amounted to $10 \mathrm{~dB}$ we may assume that embryos have mutual acoustic contact with all the other embryos in a clutch even if some embryos are mute or dead. We have to consider that sound transmission is based on a soundconducting medium. In a clutch, sound is conducted via the eggshell, lengthwise and crosswise. In industrial or commercial incubators a metal grid or a metal setter tray may serve as a sound-conducting medium. Even in the case when embryos are connected via a metal grid, a nearly perfect sound conductance was measured [28]. We suppose that most sound within the prenatal period is bone-conducted and not air conducted. As the head of the embryo has contact with the eggshell at that time, bone conduction to the embryo's ear is possible. For this, other evidence is given by 
experiments, when only air-conducted sound was used: higher sound levels were necessary when artificial clicking sounds were applied via airborne sound only [28].

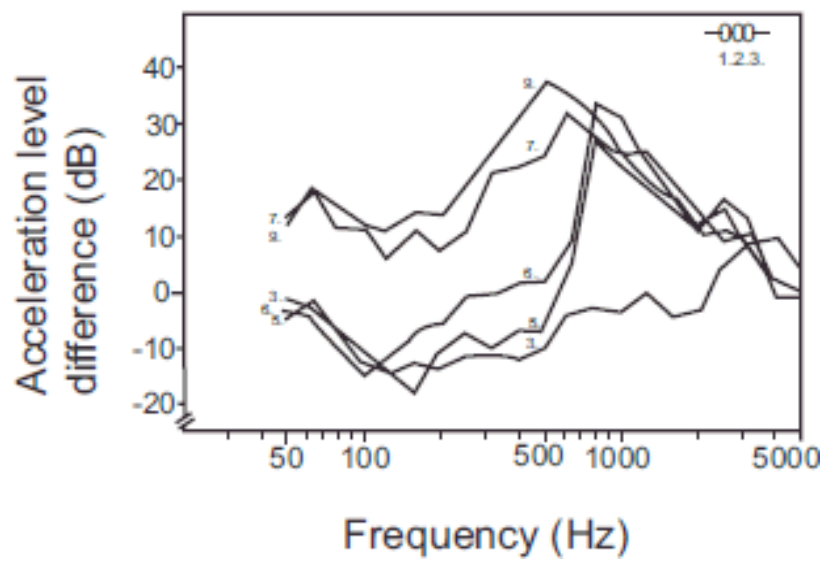

A

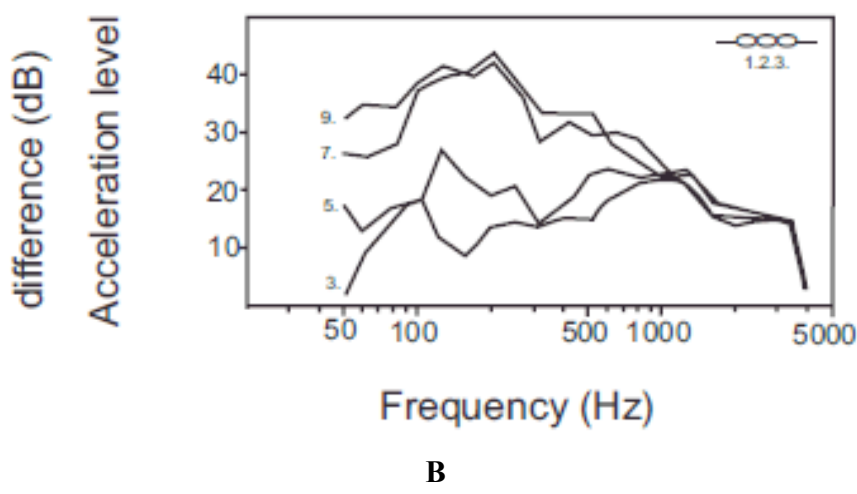

Fig. (5). Sound transmission in eggs, which had mutual eggshell contact and which were positioned linear lengthwise (A) and crosswise (B). Altogether, 10 eggs were tested for each position pattern, but examples are presented in the figures only. Acceleration level difference, measured between the first, stimulated egg and the sound-receiving egg depending on position and frequency.

\section{EMBRYONIC ACOUSTIC SIGNALS AND THEIR RELEVANCE}

\section{For Hatching Synchronization}

Since the investigations by Vince on quails [42, 43] we know that the acoustic communication by clicking sounds is an essential factor for hatching synchronization. She also discovered that the development and hatching time of quail embryos can be accelerated or decelerated, by clicking sounds [44-50]. In other precocial bird species [2, 3, 41, 54, 57], but also in semialtricial species [2] a shortening of incubation time could be achieved by stimulating the embryos with a certain artificial clicking rate. Not all of the bird species that are stimulated by clicking sounds synchronize their hatching $[36,57]$. Up to now the actual mechanism underlying clicking sound communication is not yet clear [2, 5, 36]. Recent publications in pheasants and Mallard ducks [58] support the fact of retardation and acceleration but without investigating the synchronization mechanism. Many authors [2, 3, 5, 11] suppose that acceleration and deceleration are based on different mechanisms or conclude that metabolic rates may be another mechanism to synchronize hatching as opposed to vocalizations between brood members [59]. Yet we could demonstrate in the Muscovy duck, that the mechanism which is responsible for acceleration and deceleration is the same, based on synchronization of prenatal clicking rates and therefore of breathing rates [8]. The mechanism of hatching synchronization is explained here in detail.

Synchronization starts, when the second embryo within a clutch begins to click. Within a certain, species-specific range (=German 'Mitnahmebereich' $[60,61]$ which might be translated as pulling range) embryos adapt their clicking rates to those of others. The result is a common rhythm. Muscovy duck embryos need about a minute to achieve this common rhythm (or beat). Normally, embryos try to synchronize their rhythms $1: 1$. Then the resulting clicking rate is the same in both or in all of the embryos. If the lung respiration is not sufficiently developed and the embryo cannot follow the given rhythm over a long time, the embryo initially follows the clicking beat irregularly (with breaks). Towards hatching, embryos click more and more regularly. This is also a 1:1 synchronization, but with a lower clicking rate. The phenomenon that biological rhythms may adapt to certain acoustic stimuli has been known for a long times. Thus squirrels (Sciurus vulgaris L.) can adapt their hopping frequency to certain beats of a metronome [62]. Breathing rhythms of fishes or the song of the White rumped Shama (Copsychus malabaricus Scopoli) adapt to beats of a metronome [61].

Usually, the Muscovy duck embryos in a clutch were able to synchronize their clicking rates (Figs. 6A, B) if the surrounding sound level does not exceed about $80 \mathrm{~dB}$ as measured in industrial incubators [63]. However, if the embryos had a developmental difference (beginning of clicking 25 hours more or less to the next sibling, that means 40 hours to the average of the group, this embryo hatched considerably earlier or later (one example in Fig. 6B). It can be hypothesized that small differences between the embryos as caused by, e.g., temperature [28] can be compensated.

In laboratory experiments using white noise in combination with low pass and high pass filters respectively, it was possible to eliminate clicking sound communication and allow communication by vocalization on the one hand, and to allow clicking sound communication but exclude communication by vocalization on the other hand [8]. Clicking rates and hatching synchronization were measured under different sound levels (steps of $5 \mathrm{~dB}$ ). Over a sound level of $80 \mathrm{~dB}$ (white noise low pass filter) clicking sound communication was disturbed and Muscovy duck embryos hatched asynchronously (Figs. 6C, D).

Hatching interval under desynchronizing conditions (80 $\mathrm{dB}$ ) was significantly, on average 4 times longer, than under synchronizing conditions [8]. In the Muscovy duck the mutual acoustic contact between the embryos was necessary during the whole prenatal clicking period [28].

Fig. (7) indicates an example of hatching under synchronized and desynchronized laboratory conditions and under natural and industrial conditions. It can be assumed that hatching under synchronized laboratory conditions has the same course as under natural conditions (natural breeding 


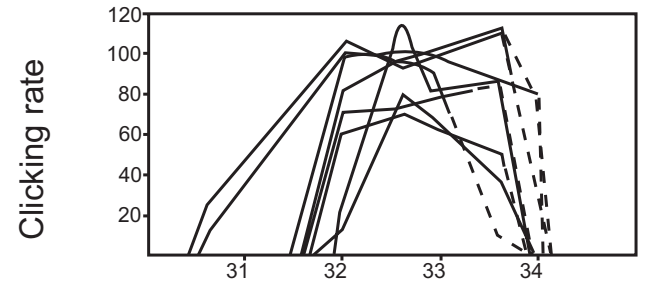

Day of incubation

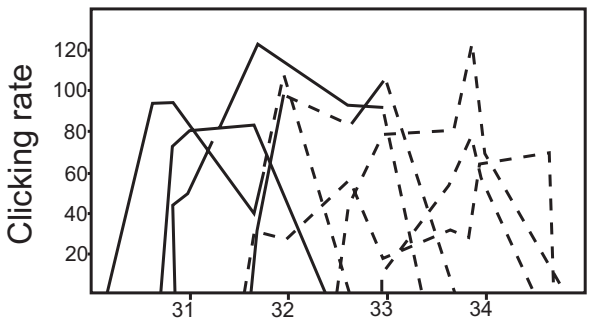

Day of incubation

C

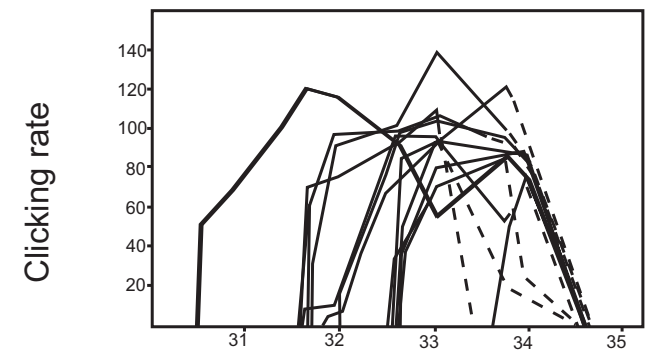

Day of incubation

B

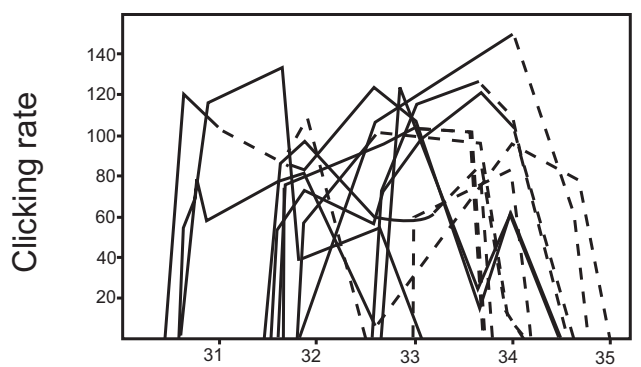

Day of incubation

D

Fig. (6). Synchronization of prenatal clicking rates of 8 (A) and 12 (B) Muscovy duck embryos under a sound pressure level in the laboratory incubator of $50 \mathrm{~dB}$ and desynchronization of prenatal clicking rates of 7 (C) and 12 (D) Muscovy duck embryos under a sound pressure level in the laboratory incubator of $80 \mathrm{~dB}$. (broken line=eggshell pipped), mutual eggshell contact, white noise low-pass-filter $<2 \mathrm{kHz}$ [28].

in holes outside, in Germany and with the domestic form) [63]. Industrial conditions seem to be more similar to desynchronized laboratory conditions [63].

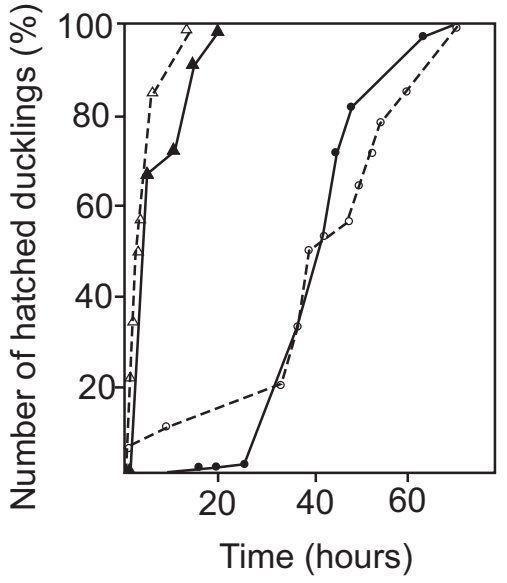

Fig. (7). Four examples of the course of hatching in the Muscovy duck: under seminatural conditions (filled triangles, solid line, $\mathrm{n}=18$ ducklings), under synchronizing laboratory conditions (unfilled triangels, broken line $\mathrm{n}=14$ ducklings), under desynchronizing laboratory conditions (unfilled circles, broken line, $\mathrm{n}=14$ ducklings, $80 \mathrm{~dB}$ ) and under industrial conditions (filled circles, solid line, $\mathrm{n}=$ 75 ducklings) [28].

Stimulating isolated embryos by artificial clicking rates (Fig. 8) an acceleration or deceleration of clicking rates and therefore of hatching was achieved as reported in the previous literature [45-47]. Fig. (8) also illustrates that an adaptation to a high clicking rate of 180 clicks per minute outside the measured 'Mitnahmebereich' of about +/- 20 click per minute was not possible and did not lead to a shortening of the incubation period. Within the period of rising clicking rates embryos could be well triggered. After pipping the eggshell-in the period of declining clicking ratesno or only little adaptation to artificial applied clicking rates could be achieved. This result completes our findings that the process of synchronization takes place in the period of rising clicking rates. By stimulating a group of embryos, which had mutual acoustic eggshell contact with artificial clicking rates (rising or a constant high rate) no better synchronization and no shortening of incubation time could be achieved $[28,63]$. This finding underlines that hatching time and hatching interval in Muscovy duck is a result of synchronizing all members within a clutch.

Besides of clicking sounds other acoustic factors are discussed concerning hatching synchronization: discomfort signals of embryos [36], contact calls of embryos [2, 36], calls of the breeding parent $[2,54,55]$, other signals when cracking the shell [36], bill clapping of the breeding parent [2], silent periods (no clicking) during cracking the eggshell [36]. Testing the effect of contact calls, discomfort signals and a combination between as well as of maternal calls in laboratory experiments with single or grouped embryos none of the mentioned acoustic signals improved hatching 
synchronization or served as a hatching releasing signal [28]. Other signals like cracking the shell or heavy movements during hatching (tested by adding embryos in this stadium) did not act as a hatching-releasing signal.

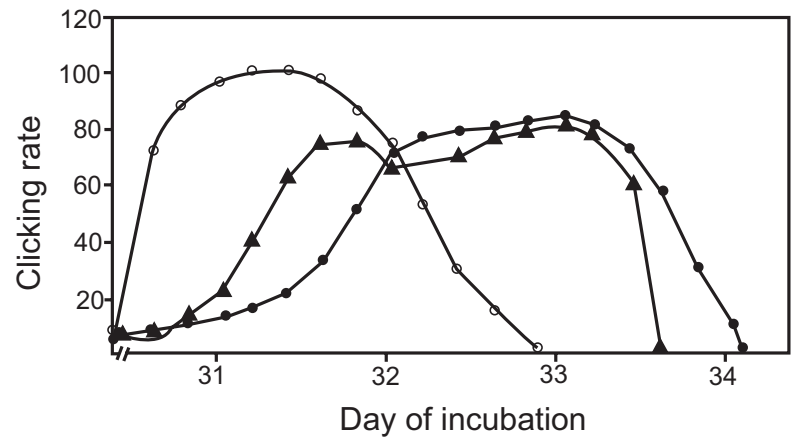

Fig. (8). Clicking rate of an isolated Muscovy duck embryo which was stimulated with each 20 clicks/min less than the actual clicking rate of the embryo (retardation) (=filled circles), clicking rate of an isolated Muscovy duck embryo which was stimulated with 20 clicks/min more than the actual clicking rate of the embryo (=unfilled circles), clicking rate of an embryo which did not adapt to the applied very high constant clicking rate of 180 clicks/min (filled triangels) [28].

Summarizing all findings there is evidence that prenatal clicking sounds in contrast to other acoustic signals play an important role for hatching synchronization in quails and Muscovy ducks. But although prenatal clicking is widespread among birds $[2,3,5]$ there are too few studies to draw conclusions for which other species it plays a major role. So clicking sound communication might be important for synchronized hatching in Nandus (Rhea americana L.) [64], but this is not proved.

Clicking sound communication is an optional synchronizing mechanism not automatically leading to synchronized hatching. To be effective clicking sound communication may depend on:

1. Length of prenatal vocalizing period $[2,3]$ and

2. Hearing ability especially maturation of efferent systems $[2,3]$ and

3. Species-specific ability to synchronize (adaptation time and 'Mitnahmebereich' $=$ pulling range) $[28,61]$ and

4. Non-acoustic synchronizing mechanisms before the prenatal vocalization period (how the bird starts breeding $[3,65]$.

All these factors interplay together. Comparing 86 bird species considering hatching synchronization [65] it can be assumed that the classification into altricial, semialtricial and precocial species has nothing to do with their ability to synchronize hatching. So skylarks (Alauda arvensis L.) and wood larks (Lullula arborea $L$.) synchronize hatching very well (with or without clicking sound communication?). Using clicking sound communication quails synchronize hatching better than Muscovy ducks despite of their shorter prenatal vocalization periods. The Nandu seems to be one of the best hatching synchronizing species (using clicking sound communication?) despite starting breeding from the first egg, which normally results in asynchronous hatching
$[3,11,65]$. Thus, further studies on more species are needed to improve our knowledge concerning the contribution of clicking sound communication to hatching synchronization.

Embryonic Acoustic Signals and their Relevance for Acoustic Communication between Embryos and between Embryos and Chicks

According to Tembrock [60], communicative signals are messages whose meaning are determined by the emitter and are sent to a recipient who is able to encode or understand this message. In this narrow sense clicking sound communication cannot be referred to as communication. Thus we focus here on vocalization to find out how an acoustic communication in a narrow sense and especially an exchange of acoustic signals develops.

Comparing vocal activity (excluding clicking sounds) of single embryos with pairs of embryos a doubled vocal activity in pairs of embryos was observed (Fig. 4). Using an iteration test, a growing overlapping rate of peep call vocalizations towards hatching, seems not to be caused by a real exchange of signals but by random overlapping of increasing vocalizations as hatching approaches [6]. Randomly combined single egg vocal activities had the same overlapping rate. Higher acoustic activity might therefore be regarded as nonspecific mutual stimulation which is supported generally by the birds` own vocalization or other stimulation within the perinatal period. Vice versa, a disruption of mutual vocal communication in the prenatal period led to lower acoustic postnatal activity and also damaged postnatal acoustic communication [28].
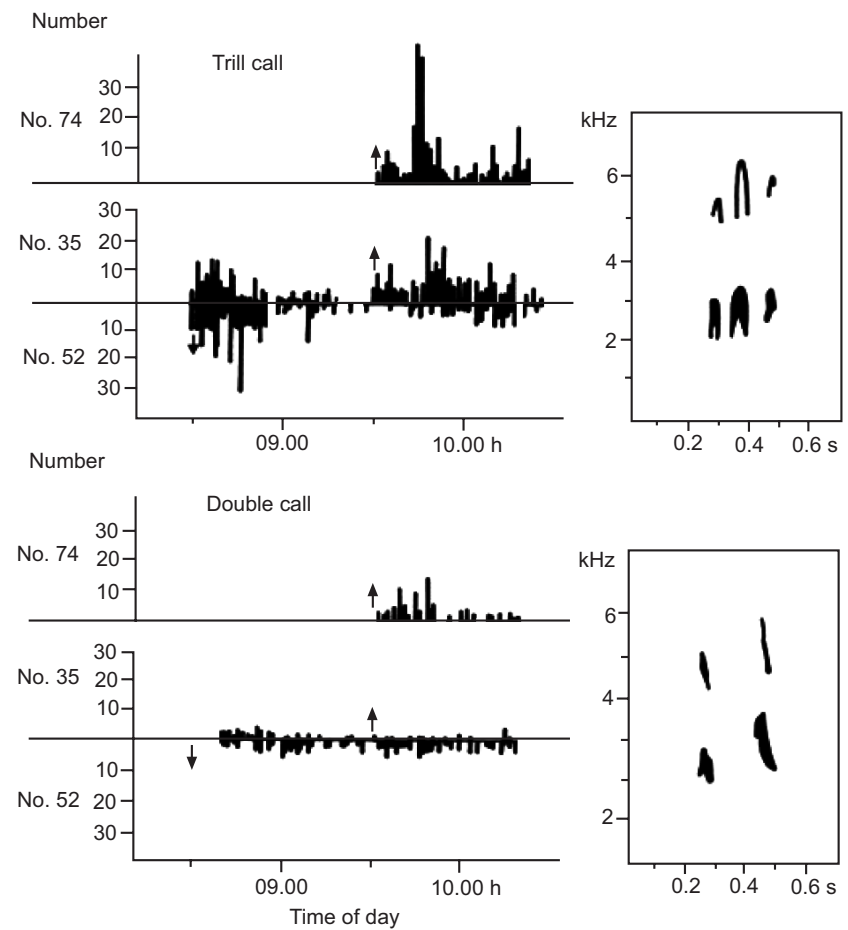

Fig. (9). Number of trill calls and double calls (number/min) in a single (No. 74) and in paired (No. 35/No. 52) Muscovy duck embryo and chick (arrow indicates hatching) [6].

Laboratory experiments [6] without a breeding parent revealed that an exchange of acoustic signals first occurs 
once the first embryo has hatched. Special communicative signals (double call and trill call) were uttered from the hatching and hatched chick in fast sequences (Fig. 9). They were directed against a neighbouring sibling in or outside the egg while the chick straightened its neck and sometimes approached the sibling or the sibling in the egg, respectively. The exchange of double ("the question") and trill calls ("the answer") took place within a few milliseconds. The embryos also answered with bill clapping. We assume that double calls act as communication-releasing signals. Isolated embryos emitted the double call only after hatching. It seems to be a contradiction that the number of double calls and trill calls was higher in isolated embryos than in pairs (Fig. 9). However, this is due to the exchange of signals in embryos/chicks with mutual acoustic contact: while listening to the signals of siblings they suppress their own vocalization. Furthermore, seeking after a sibling has to be prolonged if no answer follows. Double calls have been mentioned in other species like common guillemots in the context of embryo-maternal communication [24]. Trill calls have been mentioned as communicative signals for sibling recognition in newly hatched chicks [66]. Communicative signals around hatching are most important for imprinting. But further discussion on imprinting would go beyond the scope of this review.

\section{Embryonic Acoustic Signals and their Relevance for Acoustic Communication between Embryos/Chicks and the Breeding Parent}

Most studies deal with this aspect of perinatal communication. A detailed review is available [5]. So we focus here on some interesting facts.

One problem to decide whether a prenatal acoustic interaction or an exchange of acoustic signals between embryos and the breeding bird exists, is the close connection between vocal activity of the incubating bird and its motoric activities, mainly the close connection between grooming and turning the eggs, and the close connection between turning the egg and embryonic vocalizations [7]. These close temporal interactions between vocal activity of bird embryos and maternal behaviours like turning and resettling on a nest were not only observed in naturally incubating Muscovy ducks, but also in naturally incubating domestic chickens [52]. This fact might be an indication for an acoustic interaction [52], but this is not evidence that the embryos vocally answer parental vocalizations or vice versa. It was found that vocalization activity of the naturally breeding ducks did not differ between the periods before embryos clicked and vocalized, when embryos clicked and vocalized, and between the first and the last embryo hatched [7]. Vocal activity of the mother on the nest remained constant and was always connected with the behaviour of egg turning which did not change until all chicks hatched. In our opinion there are not enough indications for assuming an acoustic exchange between the incubating bird and the embryo. In our studies we revealed that the acoustic interaction between the breeding parent and the chicks developed quite late in the perinatal period and later than the acoustic communication among the ducklings [7]. It developed gradually during the process of exodus. When a loud noise level in the environment disrupted the mother-ducklings interaction, nest-leaving was prolonged by one day [28]. Trill calls and double calls of the embryos and food calls and contact calls suitable for encoding distance between the communication partners [67] - of the mother duck were used for establishing communication.

Up to now we do not know if and how the embryos receive the acoustic signals of the breeding parent. Measurements on hearing sensitivity [15] and experiments on sound application [28] allow the hypothesis that embryos in unpipped eggs are not able to receive the parental vocalization at least by airborne sound [15]. But it is likely that the breeding parent receives the acoustic signals of the embryos. This hypothesis is supported by our own results and the literature. We observed that the incubating Muscovy duck answered the distress calls of embryos in pipped eggs rarely [7]. This facultative acoustic reaction to embryonic calls was also characteristic for the Pekin duck [22] and for the Oystercatcher (Haematopus ostralegus L.) [68]. Although the breeding parent of the Eared Grebe (Podiceps nigricollis Brehm) does not vocalize in response to the embryos vocalization [69], embryonic vocalizations may alter the parental behaviour [69]. In others species too, vocalizations of the embryos may affect the behaviour of the parent [25,70-72] for instance egg-turning, nest building or the amount of time parents spend on the nest, manipulating the nest and nictitating or alteration of egg-turning angle [pers. observation in the Muscovy duck, 28]. The breeding parent might receive embryonic acoustic signals acoustically and also by sensing vibrations $[73,74]$. Whether embryonic vocalizations lead to hormonal changes of the breeding bird eliciting switching of parents from incubation to parental behaviour, as it was suggested by many authors [75], has yet to be proved.

Embryonic vocalizations might also serve as caresoliciting signals concerning temperature regulation [5]. Distress calls might help to restore normal incubation temperature [76]. It is well known, that the young of many bird species emit distress calls and induce maternal brooding in order to be warmed. Bird embryos such as Muscovy ducks, Eared Grebes or White Pelicans also react to cooling with higher rate of distress calling [69, 77, 78]. It seems to depend on the species and its ecological needs whether distress calls change parental behaviour or not. As already reported, the Muscovy duck as a hole-breeding species does not alter its breeding rhythm before the ducklings hatch. But especially for species breeding on or near the water more care is necessary. In these species embryonic distress call may induce special care from the parents. In the Muscovy ducks distress calls were not important concerning temperature regulation, but were used to keep the brood together $[7,79,80]$.

Also the question whether embryonic vocalizations serve for individual parent-offspring recognition, requires further research. Chicks of the Muscovy duck did not follow the food call (clucking call) automatically, as it was reported for other species e.g. the Common Pheasant (Phasianus colchicus L.) [81]. In the colonial, ground-nesting Little tern (Sterna albifrons Pall.) less parental care was given to nonvocalizing eggs than to vocalizing ones independently if they originated from foreign parents or not [75]. Newly hatched eared grebes responded to food calls of foreign 
parents as well as of their own parents [82]. In Muscovy duck we observed in one case that all ducklings changed from their own mother to a foreign mother having also newly hatched young. Thus, we might assume that the prenatal period is of less importance for parent-offspring recognition than the early postnatal period.

\section{CONCLUSIONS}

Regarding perinatal acoustic communication it is important to distinguish between clicking sound communication and communication by vocalization. Clicking sound communication can be very essential for a synchronized hatching. The mechanism underlying hatching synchronization is the synchronization of audible clicking rates, which was demonstrated for the Muscovy duck. Further studies on more species are needed to gain knowledge concerning clicking sound communication and its species-specific relevance for hatching synchronization. Embryonic vocalization may affect parental behaviour. However, more research is necessary to demonstrate the existence of prenatal acoustic communication by vocalization. Probably, acoustic communication by vocalization develops relatively late during early ontogeny.

\section{ABBREVIATION}

E-embryonic day $=$ day of incubation

\section{REFERENCES}

[1] Gottlieb G. Imprinting in relation to parental and species identification by avian neonates. J Comp Physiol Psychol 1965; 59: 86-91.

[2] Tichonov AV. Akusticeskaja signalisazia i ekologija povedenija ptic. (Russian) Lomonssow University: Moskau 1986.

[3] Tichonov AV, Morenkov ED, Fokin SJ. Povedenija i bioakustika ptic. (Russian) Lomonossow University: Moskau 1988.

[4] Evans RM. Embryonic vocalization as care-soliciting signals. Acta XIX Congr Internat Ornithol 1988:1467-75.

[5] Brua RB. Parent-offspring interactions. In: Deeming DC, Ed. Avian incubation: behaviour, environment and evolution. Oxford: University Press: Oxford UK 2002: pp. 88-99.

[6] Rumpf M, Nichelmann M. Development of prenatal acoustic interaction in the muscovy duck (Cairina moschata). Br Poult Sci 1993; 34: 287-96.

[7] Rumpf M, Nichelmann M. Zur of Ontogenese der embryomaternalen akustischen Kommunikation bei der Moschusente. Zool Jb Physiol 1992; 96: 379-94.

[8] Lauch M, Nichelmann M, Wallschläger D. Pränatale akustische Kommunikation bei der Moschusente (Cairina moschata) Mh. Vet Med 1988; 43: 865-7.

[9] Saunders JC, Coles RB, Gates GR. The development of auditory evoked responses in the cochlea and cochlea nuclei of the chick. Brain Res 1973; 63: 59-74.

[10] Konishi M. Development of auditory neuronal responses in avian embryos. Proc Nat Acad Sci USA 1973; 70: 1795-8.

[11] Golubeva TB, Tichonov AV. The voice and hearing of birds in ontogeny. Acta XVIII Congressus Internationalis Ornithologici 1985, 259-74.

[12] Dmitrieva LP, Gottlieb G. Development of brainstem auditory pathway in mallard duck embryos and hatchlings. J Comp Physiol A: Neuroethol Sensory Neural Behav Physiol 1992; 171: 665-71.

[13] Gottlieb G. Development of species identification in birds. Chicago: Univ. Chicago Press: Chicago 1971: p. 176.

[14] Gottlieb G. Conceptions of prenatal development: Behav Embryol Psychol Rev 1976; 83: 215-34.

[15] Jones TA, Jones SM, Paggett KC. Emergence of hearing in the chicken embryo. J Neurophysiol 2006; 96: 128-41.
[16] Höchel JR, Pirow R, Nichelmann M. Development of heart rate responses to acoustic stimuli in muscovy duck embryos. Comp Biochem Physiol A 2002; 131: 805-16.

[17] Gottlieb G. Development of species identification in ducklings: V. perceptual differentiation in the embryo. J Comp Physiol Psychol 1979; 93: 831-54.

[18] Gottlieb G. Development of species identification in ducklings: IX. The necessity of experiencing normal variations in embryonic auditory stimulation. Dev Psychobiol 1982; 15: 507-17.

[19] Gottlieb G. Development of species identification in ducklings: X. perceptual specifity in the wood duck embryo requires sib stimulation for maintenance. Dev Psychobiol 1982; 16: 323-33.

[20] Heaton MB. Prenatal auditory discrimination in the wood duck (Aix sponsa). Anim Behav 1972; 20: 421-4.

[21] Impekoven M. Prenatal experience of parental calls and pecking in the laughing gull (Larus atricilla). Anim Behav 1971; 19: 475-86.

[22] Impekoven M. Response-contingent prenatal experience of maternal calls in the pekin duck (Anas platyrhynchos). Anim Behav 1973; 21: 164-8.

[23] Oppenheim RW. Some aspects of embryonic behaviour in birds: a comparative study of altricial and precocial birds. Anim Behav 1970; 18: 335-52.

[24] Tschanz B. Beobachtungen und Experimente zur Entstehung der persönlichen Beziehung zwischen Jungvogel und Eltern bei Trottellummen. Verh Schweiz Naturforsch Ges 1964; 211-6.

[25] Tschanz B. Trottellummen. Die Entstehung der persönlichen Beziehung zwischen Jungvogel und Eltern. Berlin und Hamburg: Paul Parey 1968.

[26] Rubel EW. Ontogeny of structure and function in the vertebrate auditory system. In: Jacobson M, Ed. Handbook of sensory physiology: development of sensory stimulation. Berlin: Springer 1978; vol. 9: pp. 135-237.

[27] Prinzinger R, Dietz V, Bringer D. Internal pipping (IP): obligat oder fakultativ für einen erfolgreichen Schlupf? J Ornithol 2000; 141: 191-202.

[28] Lauch M. Prä- und perinatale akustische Kommunikation bei der Moschusente (Cairina moschata). PhD theses, HumboldtUniversity: Berlin 1989.

[29] Driver P. Parent/young relationship in the ontogeny of ducklings. Anim Behav 1962; 10: 388-9.

[30] Kirkman FB. The birth of a black-headed gull. Br Birds 1931; 24: 283-91.

[31] Weaver RL. Reproduction in english sparrows. Auk 1943; 60: 6274.

[32] Collias NE. The development of social behavior in birds. Auk 1952; 69: 127-59.

[33] Veterany L, Hluchy S, Weis J. The influence of an artificial sound stimulation on the chicken hatching from incubated eggs with the variant of weight. Die Bodenkultur 1999; 50: 185-9.

[34] Breed FS. The development of certain instincts and habits in chicks. Behav Monogr 1911; 1: 1-78.

[35] Vince MA, Salter SH. Respiration and clicking in quail embryos. Nature 1967; 216: 582-3.

[36] Vince MA. Embryonic communication, respiration and synchronisation. In: Hinde RA, Ed. Bird vocalization. Cambridge: Univ Press 1969: pp. 233-60.

[37] Mc Coshen JA, Thompson RP. A study of clicking and its source in some avian species. Can J Zool 1968; 46:169-72.

[38] Hansen P. Clicking in avian embryos and young-a hypothesis on the source. Biophon 1974; 111: 2-4.

[39] Chappell MA, Bucher TL. Effects of temperature and altitude on ventilation and gas exchange in chukars (Alectoris chukar). J Comp Physiol B 1987; 157: 129-36.

[40] Tzschentke B. Attainment of thermoregulation as affected by environmental factors. Poult Sci 2007; 86: 1025-36.

[41] Vince MA. Effects of external stimulation on the onset of lung ventilation and the time of hatching in the fowl, duck and goose. $\mathrm{Br}$ Poult Sci 1973; 14, 389-401.

[42] Vince MA. Synchronisation of hatching in american bobwhite quail (Colinus virgineanus). Nature 1964; 203: 1192-3.

[43] Vince MA. Social facilitation of hatching in the bobwhite quail Anim Behav 1964; 12: 531-4.

[44] Vince MA. Potential stimulation produced by avian embryos. Anim Behav 1966; 14: 34-40.

[45] Vince MA. Artificial acceleration of hatching in quail embryos. Anim Behav 1966; 14: 389-94. 
[46] Vince MA. Retardation as a factor in the synchronisation of hatching. Anim Behav 1968; 16: 332-5.

[47] Vince MA. Effect of rate of stimulation on hatching in japanese quail. Br Poult Sci 1968; 9: 87-91.

[48] Vince MA. Communication between quail embryos and the synchronization of hatching. Proc XV Ornithol Congr 1972: 32433.

[49] Vince MA, Cheng RCH. The retardation of hatching in japanese quail. Anim Behav 1970; 18: 210-14.

[50] Vince MA, Ockleford E, Reader M. The synchronisation of hatching in quail embryos: aspects of development affected by a retarding stimulus. J Exp Zool 1984; 229: 273-82.

[51] Forsythe DM. Clicking in the egg-young of the long-billed curlew. Wilson Bull 1971; 83: 441-2.

[52] Tuculescu RA, Griswold JG. Prehatching interactions in domestic chicken. Anim Behav 1983; 31: 1-10.

[53] Gottlieb G, Vandenbergh JG. Ontogeny of vocalization in duck and chick embryos. J Exp Zool 1968; 168: 307-26.

[54] Iljicev VD, Tichonov AV. Biologiceskije osnovy upravlenija povedeniem ptic. 1. kurinye (Galliformes). Zool Zhurn 1979; 58: 1021-32.

[55] Iljicev VD, Tichonov AV. Biologiceskije osnovy upravlenija povedeniem ptic. 2. plastincatokljuvye (Anseriformes). Zool Zhurn 1979; 58: 1172-82.

[56] Gräns A, Altimiras J. Ontogeny of vocalizations and movements in response to cooling in chickens fetuses. Physiol Behav 2007; 91: 229-39.

[57] White NR. Effects of embryonic auditory stimulation on hatch time in the domestic chick. Bird Behav 1984; 5: 122-6.

[58] Persson I, Andersson G. Intraclutch hatch synchronization in pheasants and mallard ducks. Ethology 1999; 105: 1087-96.

[59] Nicolai CA, Sedinger S, Wege ML. Regulation of development time and hatch synchronization in black brant (Branta bernicla nigricans). Funct Ecol 2004; 18: 475-82.

[60] Tembrock G. Verhaltensbiologie. Wörterbücher der Biologie. Jena: Gustav Fischer 1978.

[61] Kneutgen J. Beobachtungen über die Anpassung von Verhaltensweisen an gleichförmige akustische Reize. Z Tierpsychol 1964; 21: 763-79.

[62] Eibl-Eibesfeldt I. Beobachtungen zur Fortpflanzungsbiologie und Jugendentwicklung des Eichhörnchens (Sciurus vulgaris). Z. Tierpsychol 1951; 8: 370-400.

[63] Nichelmann M, Langbein J, Lauch M. Bedeutung und of Mechanismen des perinatalen Verhaltens. Aktuelle Arbeiten zur artgemäßen Tierhaltung 1989. KTBL-Schrift 342; Landwirtschaftsverlag Münster-Hiltrup, Germany 1990: pp. 31028.

[64] Vleck D, Vleck, CM, Hoyt DF. Physiological correlates of synchronous hatching in rhea eggs (Rhea americana). Acta XVIII Internationalis Congressus Ornithologici Moskau 1985; pp. 864-72.
[65] Rumpf M. Synchronisationsindex als $\mathrm{Ma} \beta$ für die Schlupfsynchronisation. Acta Ornithoecol 1992; Jena 2, 4: 335-40.

[66] Vallortigara G, Zanforlin M. A newborn chick`s companion.monitore. Zool Ital 1986; 20: 63-73.

[67] Kondo N, Watanabe S. Contact calls: information and social function. Jpn Psychol Res 2009; 51: 197-208.

[68] Norton-Griffiths M. The organization, control and development of parental feeding in the oystercatcher (Haematopus ostralegus). Behaviour 1969; 34: 55-114.

[69] Brua RB, Nuechterlein GL, Buitron D. Vocal response of eared grebe embryos to egg cooling and egg turning. Auk 1996; 113: 525-33.

[70] Oliver WLR, Mallet MM, Singleton DR, Ellet JS. Observations on the reproductive behaviour of a captive colony of bare-faced ibis Geronticus eremita. Dodo. J Jersey Wildl Preserv Trust 1979; 16: 11-35.

[71] Sahin R. Beitrag zum Fortpflanzungsverhalten der freilebenden Waldrappe (Geronticus eremita L.) in der Türkei. 3. Mitt.: Eiablage, Brüten und Schlüpfen. Ökol Vögel 1983; 5: 255-62.

[72] Pegoraro K. Zur Ethologie des Waldrapps (Geronticus eremita); Beobachtungen in Volieren und im Freiland (Türkei, Marokko). Diss. Univ. Innsbruck, 1992.

[73] Schildmacher H. Untersuchungen über die Funktion der Herbstschen Körperchen. J Ornithol 1931; 74: 374-415.

[74] Schwartzkopff J. Über Sitz und Leistung von Gehör und Vibrationssinn bei Vögeln. Z Vergl Physiol 1949; 31: 527-608.

[75] Saino N, Fasola M. The function of embryonic vocalization in the little tern (Sterna albifrons) Ethology 1996; 102: 265-71.

[76] Evans RM. Egg temperature and parental behavior during the transition from incubation to brooding in the american white pelican. Auk 1989; 106: 26-33.

[77] Nichelmann M, Tzschentke B. Ontogeny of thermoregulation during the prenatal period in birds. Ann NY Acad Sci 1997; 813: 78-86.

[78] Evans RM. Vocal regulation of temperature by avian embryos: a laboratory study with pipped eggs of the american white pelican. Anim Behav 1990; 40: 963-8.

[79] Lorenz K. Der Kumpan in der Umwelt des Vogels. J Ornithol 1935; 83: 137-213

[80] Gaioni SJ, Applebaum S, Goldsmith J. The response of young peking ducklings to sibling distress calls. Dev Psychobiol 1983; 16 : 423-37.

[81] Bailey ED, Ralph KD. The effects of embryonic exposure to pheasant vocalizations in later call identifications by chicks. Can J Zool 1975; 58: 1028-34.

[82] Buitrin D, Nuechterlein GL. Parent-young vocal communication in eared grebes. Behaviour 1993; 122: 195-230.

Received: March 03, 2010

Revised: June 09, 2010

Accepted: June 20,2010

(C) Rumpf and Tzschentke; Licensee Bentham Open.

This is an open access article licensed under the terms of the Creative Commons Attribution Non-Commercial License (http://creativecommons.org/licenses/by$\mathrm{nc} / 3.0 /$ ), which permits unrestricted, non-commercial use, distribution and reproduction in any medium, provided the work is properly cited. 